\title{
Fracture Mechanics of Concrete
}

\section{FOREWORD}

This special issue of $S \bar{a} d h a n \bar{a}$ is rightly dedicated to the fracture mechanics of concrete. In particular, the size effect is highlighted. As appropriately pointed out in the first international conference on fracture mechanics of concrete structures, FraMCos-I, organized by Z P Bažant, at Breckenridge, Colorado in 1992, fracture mechanics of concrete can be called the 3rd phase in the evolution of concrete structures. Since then the number of published papers on the topic have increased several-fold. Going back in the memory pipeline, it was M F Kaplan ${ }^{1}$ (in 1961) who tried to obtain the fracture toughness of concrete. It was observed later that there was no consistent value of fracture toughness of concrete. Therefore, towards the early eighties, nonlinear fracture theories were proposed. The process zone ahead of the crack tip was identified as having an important role to play in the nonlinear fracture mechanics of concrete. A little later, it led to the size effect, which as proposed in fracture mechanics is different from Weibull's hypothesis for size effect. Later, there was a workshop on the size effect in concrete structures, organized by H Mihashi, H Okamura and Z P Bažant, at Sendai, Japan in 1993. Various international committees were formed, the earliest one being the RILEM Committee chaired by F H Wittmann. Several other important meetings took place at different places like the international workshop at Locarno, Switzerland in September, 1990 organised by Wittmann and Dungar, and the international workshop on concrete fracture, organised by A Carpinteri, at Torino in October 1991.

In recent years, as high performance concrete is gaining importance, its fracture behaviour is being studied with great seriousness. High strength concrete is nearer to linear theories of fracture and is relatively more brittle. The challenge is whether one can make high strength concrete relatively more ductile by improving the cohesiveness of cracks.

The next question is how to bring the size effect into codes of practice on the design of reinforced concrete structures, since large structures like dams, nuclear reactors, very tall towers, do contain large sized members. The issue to be addressed is whether it is in order to assume the same tensile strength as obtained in the laboratory for the full scale structure also. This special issue is intended to focus on the above features. Fracture mechanics of concrete has yet to go a long way. One may say that a complete textbook in the strict sense of the term came out only as recently as in 1995, written by B L Karihaloo.

The contributors to this special issue, F H Wittmann, A Carpinteri and B Chiaia, V E Saouma and D Natekar, B Karihaloo and Q Z Xiao, Jin Keun Kim and Seong Tae Yi, and Vladimir Cervenka et al, are all leading researchers in the field of fracture mechanics of concrete. This special issue will certainly be an important document relating to the latest research on the subject. It will also help active researchers to pursue further research on the topic.

\footnotetext{
${ }^{1}$ Crack propagation and the fracture of concrete. ACI Journal 58 (No.11), 1961
} 
In fact, in the literature many practical cases involving plain and reinforced concrete structures have been studied from the point of view of fracture mechanics. Study of crack growth in massive concrete dams and bridges can be cited as good examples. Most importantly the analysis of the recent collapse of the World Trade Center in New York by Z P Bažant \& Yong $Z_{\text {hou }}{ }^{2}$, mentions that if fracture at the plastic hinges were considered, it would give more precise estimates of the hinge rotations. The kinetic energy of the falling upper part of the building, if absorbed totally in the plastic hinges, would prevent any further fall. To estimate the energy absorbed by a plastic hinge needs full knowledge of fracture as well. The authors in the above paper suggest a study of thermal fracture and further suggest use of refractory ceramics for buildings to prevent such collapses.

F H Wittmann, in his paper in this issue, shows that it is possible to predict cracking due to shrinkage and further how important it is to control this cracking and achieve the necessary durability. Massive concrete foundations are common in practice. When deformations have to be controlled at micro levels, as in foundations for antenna facilities connected with spacecraft, shrinkage deformations need to be precisely determined. Shrinkage effects are particularly significant in high strength concrete.

Alberto Carpinteri \& Bernardino Chiaia discuss how to predict decrease in strength and increase in embrittlement with increase in size of unnotched structures, which is more realistic. Karihaloo \& Xiao also deal with decrease in strength with increase in size and show some improvements in Karihaloo's size effect formula. Saouma \& Natekar discuss a novel approach to derive Bazant's size effect law from the Newtonian approach based on local stress intensity factors.

While the size effect mentioned hitherto deals with decrease in tensile strength, Kim \& Yi show in their paper that flexural compressive strength also decreases with increasing size. They bring out effects of length and depth separately and, more importantly, say that in view of the above, current design procedure should be reviewed.

The paper by Cervenka et al talks about a software tool for nonlinear fracture. Such commercial codes to simulate nonlinear fracture of plain and reinforced concrete are very important these days for quick assessment of the safety of a given structure.

I sincerely thank all the contributors to this special issue. I also thank Dr. Gangan Prathap, Editor, for his interest in bringing out a special issue of $S \bar{a} d h a n \bar{a}$ dedicated to the fracture mechanics of concrete and giving me this opportunity to work as the guest editor. I also thank Prof R N Iyengar of the Indian Institute of Science, for his encouragement. I finally thank Ms. Shashikala and the staff of Sādhanā for the timely and efficient editorial help. I also thank my ALTECH project staff for their assistance.

August 2002

B K RAGHU PRASAD

Guest Editor

Dept. of Civil Engineering

Indian Institute of Science

Bangalore 560012

\footnotetext{
${ }^{2}$ Why did the World Trade Center Collapse? - Simple Analysis. Journal of Engg. Mechanics, (ASCE) 128 (No.1) January 2002
} 